Original Research

\title{
Variation in Runoff Series Regimes and the Impacts of Human Activities in the Upper Yellow River Basin
}

\author{
Yao Chen ${ }^{1,2 *}$, Hui Qian ${ }^{1,2}$ \\ ${ }^{1}$ School of Environmental Science and Engineering, Chang'an University, Xi'an, China; \\ ${ }^{2}$ Key Laboratory of Subsurface Hydrology and Ecological Effect in Arid Region of Ministry of Education, \\ Chang'an University, Xi'an, China
}

Received: 15 November 2017

Accepted: 4 March 2018

\begin{abstract}
It is important to manage water resources of the upper Yellow River basin for the new Silk Road economic belt. In recent decades, under the combined human activities and influence of climate, the hydrologic regime of the upper Yellow River basin shows remarkable variations that have caused many issues. So potential human indicated influence has been drawing increasing attention from hydrologists and local governments. The aim of this study is to determine the changes in the hydrological characteristic parameters and mean annual runoff series of the upper Yellow River basin. This paper took the representative Lanzhou Station in the upstream Yellow River as an example, used the TFPW-MK mutation test and rank sum test to analyze the location of the variation points of hydrological series. By contrasting two different analysis results between natural and measured river runoff series, the impacts of human activities on the long-term hydrological regime were investigated. The variation range of hydrological ecological indexes before and after variation were analyzed by the method of indicators of hydrologic alteration (IHA). The results show: a) the hydrological series of Lanzhou Station is a significant decreasing trend can be observed in the natural stream flow series in 1985 with a high degree of hydrological variability, while human activities play an important role; b) various ecological indicators have changed in different degrees that have caused the deterioration of ecological conditions around 1985; and c) continuous decreasing stream flow in the upper Yellow River basin will trigger serious shortages of fresh water in the future, which may challenge the sustainability and safety of water resource development in the river basin, and should be paid great attention before 2020. Variation analysis and diagnosis of eco-hydrological indexes in the upper reaches of the Yellow River can provide a basis for the development, utilization, and protection of water resources in this area.
\end{abstract}

Keywords: trend analysis, Yellow River basin, TFPW-MK, human activities

*e-mail: chenyao3715@chd.edu.cn 


\section{Introduction}

For economic globalization, the "silk road economic belt" is crowned with a new mission at present. We know that the belt is aiming to bring immense economic benefit to the undeveloped northwestern part of China and Eurasian countries, especially central Asian countries. However, in recent years, due to the natural environment and human activities, the variability of many rivers has been greater than that over the history of the river [1-6]. This phenomenon is no exception in our country, with the upper reaches of the Yellow River making this particularly evident. The Yellow River is the second longest river in China, and it has been a major source of water for irrigated agriculture, households, industry, and ecological services along the river for centuries. Stream flow of the Yellow River is one of the most important variables for ecological environment and human activities. Its spatial and temporal variations directly influence the local as well as global water, energy, and matter cycle [7-10]. So in this paper we can study the trend and long-range correlation characteristics of runoff time series. For that, it can guide the regional water resources management and effectively utilize water resources [11]. In the last decade much research concerning the trend and longrange correlation characteristics has been published [1214].

To date, the upper reaches of the Yellow River runoff is decreasing overall. Our government estimates that 207 290 million cubic meters for the Yellow annual average flow with less than normal $15.6 \%$ after 1990 [15]. The variability of stream flow was influenced by the huge engineering project and climate change [16].

Many ecologists have recognized that flow regimes and river discharge are the primary drivers for many fundamental ecological processes in river ecosystems [17]. Many problems have occurred, such as worsening water pollution, reduced biodiversity, and conflicts between water supply and demand [18-21]. Therefore, we should pay more attention to the ecological responses of rivers to hydrological alteration.

Under natural conditions hydrological processes are extremely complex and variable, and they are influenced by many physical factors, such as climate condition and underlying surface conditions [16]. However, with human demand for water rapidly increasing, human activities play an increasingly important role in the hydrological regime of river and added complexities to river hydrological processes [22-23]. On account of that, to analyze future changes in river hydrological regimes has become very difficult. Further analysis of hydrological variability is of great significance to river eco-hydrological dissipation. In recent years many statistical methods have been provided to detect hydrological changes and find the causes of variations [24-26]: moving average method, Mann-Kendall test, rank correlation test, least square method, slope estimator method, student's t test, etc. [27]. Being free from the normal distribution for sequences, nonparametric hypothesis testing methods are used with more prevalence. In recent years, the mix of the bootstrap method and conventional sampling method comes to be applied in trend-identification research along with the development of computing capability. Nevertheless, how to accurately detect the trend of hydrological sequences is still a hot and challenging issue in the current scientific research. It is often the case that different statistical methods require different assumptions (such as sequence distribution, homogeneity, etc.). When the hydrological data do not meet its assumptions as required before, there will be an inevitability about the deviation of the test results. Furthermore, such factors as the autocorrelation of sequences and outliers will also affect the rationality of the test results obtained by the above-mentioned methods [28-29].

However, there are few researches on the variation diagnosis, classification, and index recognition of the Lanzhou section runoff series the in the upper reaches of the Yellow River, which are based on the systematic thinking and knowledge regarding these factors, including degrees, influence ranges, and the driving forces of hydrology necessary for hydraulic planning and design processes, as well as for future studies [30-33].

The objective of this study is to analyze changes in the hydrological regime. Based on the importance of the hydrological and ecological variations of the upper Yellow River Basin and its special significance, this paper further considers the research methods and ideas. Many studies have explored the long-range correlation characteristics of hydrological time series.

In this study, the TFPW-MK mutation testing method and the rank sum test method are used to analyze the representative runoff variation in the upper reaches of the Yellow River. This aims at avoiding the defects of the single variation analysis method and increasing the reliability of the variance analysis result; furthermore, the IHA [34] hydrological index changing method is adopted to analyze hydrological and ecological situations before and after variation.

By the previous discussion, the present study will be significant for: 1) detecting the trend characteristics of runoff changes of the Yellow River; 2) determining the hydrological regime under the impact of human activities, such as degrees, influence ranges, and driving forces of hydrological variations, and further solve the hydraulic planning to provide advice; (3) contributing to adjusting future-oriented water resource management strategies for the mathematical model.

\section{Material and Methods}

\section{Study Area and Data}

The Yellow River (Fig. 1) is the second-longest river in China and the sixth-longest in the world at 


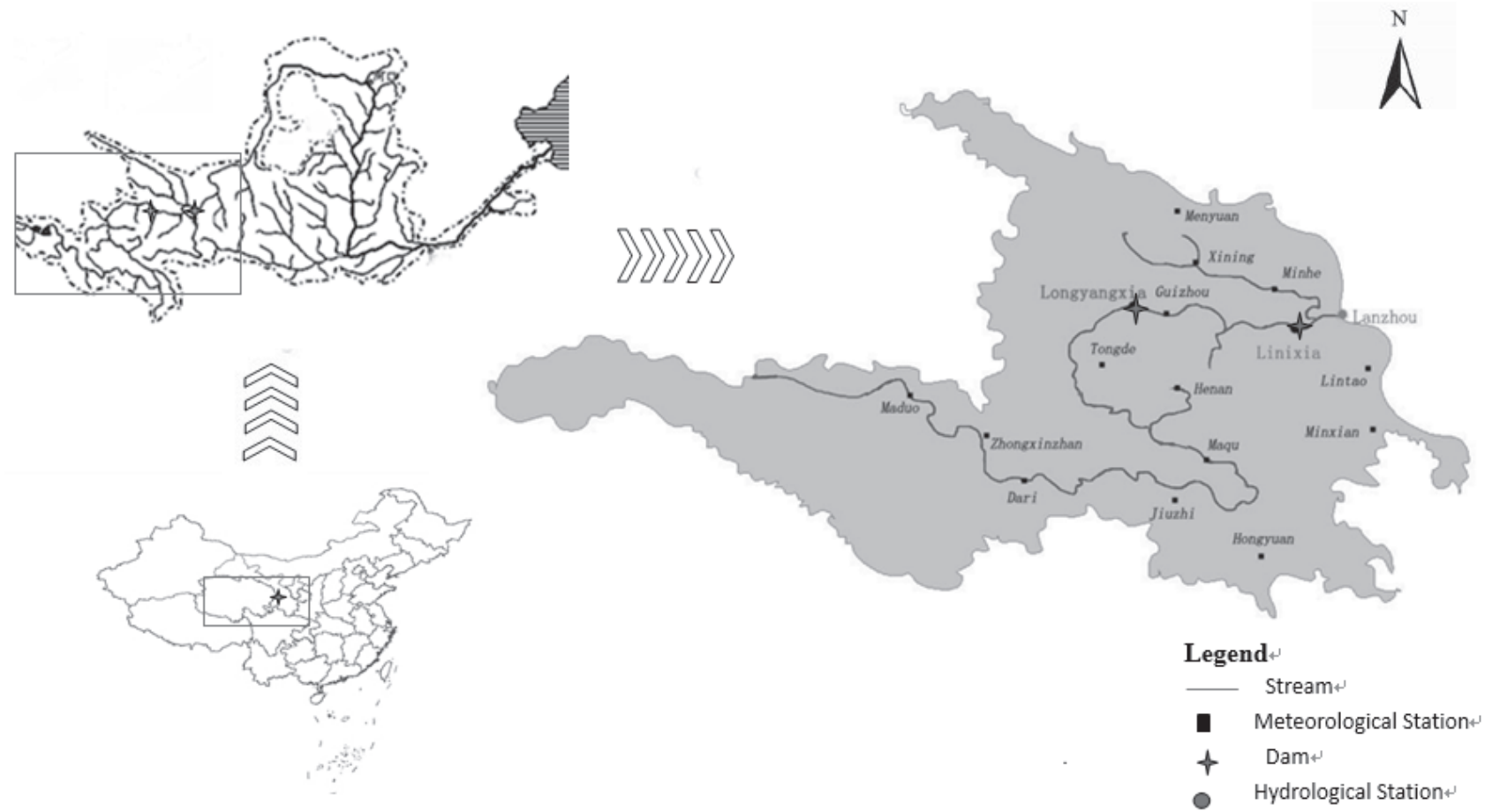

Fig. 1. Study area and relevant hydrological stations.

$5,464 \mathrm{~km}$. Originating in the Bayan Har Mountains in Qinghai Province in western China, it flows through nine provinces of China and empties into the Bohai Sea. The Yellow River is called the "cradle of Chinese civilization" as its basin is the birthplace of the northern Chinese civilizations and was the most prosperous region in early Chinese history. However, pollution, hydropower, intensive water extraction for human consumption, agriculture, and industrial use have been taking their toll on the river for the past several years, earning it the unenviable name "China's Sorrow." So the Yellow River is faced with many problems, such as the shrinkage of river channels, sediment aggradation, and wetland degradation.

The study mainly concentrates on the upstream reach of the river, and it is located in the new Silk Road economic belt (Fig. 1), and the basin will make a great influence on the building of the economic belt in northwestern China in the future. The upstream reach of the river is from the source to the Hekou town of Toketo county, Inner Mongolia. It has a total length of $3472 \mathrm{~km}$ from the estuary and a total area of $386000 \mathrm{~km}^{2}$, accounting for $51.46 \%$ of the entire area of the Yellow River basin. The study area belongs to the mountain plateau climate system, which has the characteristics of a typical continental climate in the cold seasons and a southwest monsoon climate in the warm seasons, and the mean annual temperature is $2.68^{\circ} \mathrm{C}$, with 2554.7 hours of sunshine duration, $446 \mathrm{~mm}$ of precipitation, and $1428.9 \mathrm{~mm}$ of evaporation. The annual runoff volume at Lanzhou station is 32.99 billion $\mathrm{m}^{3}$, and accounts for $61.69 \%$ of the entire Yellow River basin (1956-2000). In this study the basin is clear, and sediment accounts for $8 \%$ of the entire river.

According to the characteristics of hydrological and ecological zoning in the existing achievements, this study considers the control range of the regulating reservoirs at different locations and the distribution of the main control section. In this study, there are 2 main large-scale reservoirs in the area, as shown in Fig. 1. The upper reaches of the Yellow River are divided into the source of the Yellow River - Lanzhou reach, Lanzhou - estuary Lanzhou - estuary section. In this paper, the Lanzhou section of the Liujiaxia Hydropower Station (Fig. 1) is selected, and the change of the flow rate can reflect the influence of the joint operation of Longyangxia and Liujiaxia on flow characteristics, which will lead to the supply of irrigation, water, and sediment relations and ecological protection.

\section{Data}

We get some information that includes the time of construction, the drainage area, and the total water capacity about the two large-scale reservoirs from Table 1. Three stages were the unregulated period (1950-1969.10), a period regulated by a single reservoir (1970-1986.9), and a period regulated by cascade reservoirs (1987-2010), respectively, in which the unregulated period was also taken as being natural. The daily measured streamflow data at the Lanzhou gauge, covering a period 1950-2012, were obtained from the hydrological bureau of the Yellow River Conservancy Commission (YRCC). 
Table 1. Major water reservoirs in the upper Yellow River basin.

\begin{tabular}{|c|c|c|c|}
\hline Station & Time of construction/impoundment & Drainage area $\left(\mathrm{km}^{2}\right)$ & Total capacity $\left(108 \mathrm{~m}^{3}\right)$ \\
\hline Longyangxia & 1969.11 & 131,420 & 246 \\
\hline Liujiaxia & 1986.1 & 182,000 & 57 \\
\hline
\end{tabular}

\section{Methodologies}

Three approaches are used in this study: the trendfree pre-whitening Mann-Kendall (TFPW-MK) test, the moving rank sum test (Mann-Whitney U Test), and the range of variability approach (RVA).

For the determined appropriate points, this passage compares the results of the three methods.

\section{Mann-Kendall test with Trend-Free Pre-Whitening}

Rank-based Mann-Kendall test [35-36] is a nonparametric statistical method that may be used for testing trends and analyzing change points. Characterized by simple structure and convenient calculations, it is neither subject to certain distribution nor disturbed by outliers, so it is one of the common ways for analyzing change points of hydrological series, but impacted by trends. After their comparative analysis of ordinary Mann-Kendall test and special Mann-Kendall test with trend free pre-whitening, Zhang Danwu et al. [37] have concluded that the variance of the series will increase or decline if there are positive or negative autocorrelations. As a result, the probability of rejecting original hypothesis will be increased or decreased at a certain significance level. Meanwhile, trends of the series are associated with the higher value of their autocorrelation coefficients. For series with noticeable trends, their autocorrelation coefficients shall be estimated after trend removal.

In performing the Mann-Kendall test with trendfree pre-whitening (TFPW-MK) [38-40], the impacts of noticeable trends of data series upon estimation of autocorrelation coefficients are taken into account. The trend free pre-whitening eliminates impacts of trends upon autocorrelation coefficients and tests data series more accurately. The steps are as follows:

1) Assuming that the series is composed of linear trends and AR (1), the linear trends of new sample data are calculated by methods proposed by Theil [37] and Sen [38] $\beta$ :

$$
\beta=\operatorname{median}(), \forall \mathrm{j}<\mathrm{I}
$$

2) Remove trends and thus form trend-free series $Y_{t}$ :

$$
Y_{t}=X_{t}-T_{t}=X_{t}-\beta t
$$

3) Calculate the first-order autocorrelation coefficient $\mathrm{rl}$ of the series $Y_{t}$ and remove its autocorrelation terms:

$$
Y_{t}^{\prime}=Y_{t}-r_{1} Y_{t-1}
$$

4) By recovering trend $Y_{t}$, a new series without autocorrelation impacts is obtained as follows:

$$
Y_{t}^{\prime \prime}=Y_{t}^{\prime \prime}+T_{t}
$$

This series is no longer impacted by autocorrelation.

Mann-Kendall test is performed on the new series after its trend-free pre-whitening in order to further test the variation of the series. The statistics are defined as follows:

$$
U B_{k}=\frac{\left[s_{k}-E\left(s_{k}\right)\right]}{\sqrt{\operatorname{Var}\left(s_{k}\right)}}
$$

..where:

$$
\begin{gathered}
S_{k}=\sum_{i=1}^{k} \sum_{j}^{i-1} a_{i j} \quad(k=1,2, \ldots n) \\
\left\{\begin{array}{cc}
a_{i j}=1 \quad x_{i}>x_{j}(j=1,2,3, \ldots i) \\
a_{i j}=0 \quad x_{i}>x_{j}
\end{array}\right. \\
E\left(S_{k}\right)=k(k+1) / 4 \\
\operatorname{Var}\left(S_{k}\right)=k(k-1)(2 k+5) / 72
\end{gathered}
$$

The time series $\mathrm{x}$ is arranged in descending order and calculated by the above formula. Meanwhile, an expression is obtained as follows:

$$
U F_{k}=-U B_{k}^{\prime}, k^{\prime}=n+1-k \quad k=1,2, \ldots n
$$

By analyzing statistical series $U F_{k}$ and $U B_{k}$, the changes to the trends of the series $\mathrm{x}$ may be further analyzed, while time and areas of mutations are clarified. Provided that the value of $U F_{k}$ is greater than 0 , the series tend to ascend, but descend if the value is below 0 . The curves constituted by both statistical series are marked as $U F$ and $U B$, respectively. When both curves go beyond the critical line, the upward or downward trends will be evident. In case of any intersection point between two curves, which is between the critical lines, the moment at which both curves intersect is just the moment when the mutation begins. 
The difference between this method and other test methods consists of the fact that the intersection point of two curves is generally between two years during the test. In other words, the mutation doesn't occur at certain exact points. Thus, we need to select one of two points as the point of mutation by a certain approach.

\section{Moving Rank Sum Test (Mann-Whitney U Test)}

Moving rank sum test, also known as Mann-Whitney $\mathrm{U}$ test, is a nonparametric statistical method that neither depends upon general types of distribution nor derives general parameters, but intends to test whether significant differences exist in the distribution of two or more observed variables. Since rank sum test is highly applicable to and efficient for diagnosing points of mutations (mean, $\mathrm{Cv}, \mathrm{Cs}$ ), it is performed in this paper for verifying whether the results of the TFPW-MK test are reasonable or not. The calculation steps of the moving rank sum test are as follows [33-34]:

Step 1: Investigate the general distribution functions $F_{p r e}(x)$ and $F_{p o s t}(x)$ of the series before and after the point. Two samples with a size of $n_{\text {pre }}$ and $n_{\text {post }}$ are respectively sampled from $F_{\text {pre }}(x)$ and $F_{\text {post }}(x)$. The original hypothesis is that $F_{\text {pre }}(x)=F_{\text {post }}(x)$ shall be tested.

Step 2: Arrange two groups of data in descending order and uniformly compile ranks of these data in an ascending order. If any raw data are the same, they can be categorized as a group without calculating the average rank. The same intergroup data are processed based on the average rank. Step 3: Calculate the rank sum and determine test statistics. When the size of two samples differs, the smaller size will be $n_{1}$, while the greater size shall be $n_{2}$. The rank sum of the smaller sample is a test statistic $T_{1}$, and the rank sum of the greater sample is $T_{2}$. Provided that the size of both samples is the same, then $n_{1}=n_{2}$. The rank sum test statistic is $T_{1}$ in any group, but $T_{2}$ in the other group. Step 4: Calculate and reach conclusions by deduction. The statistic $U$ is calculated as follows:

$$
\begin{gathered}
U=n_{1} n_{2}+\frac{n_{1}\left(n_{1}+1\right)}{2}-T_{1} \\
U=n_{1} n_{2}+\frac{n_{2}\left(n_{2}+1\right)}{2}-T_{2}
\end{gathered}
$$

...where $U$ is the statistic, $n_{1}$ is the smaller sample size, $n_{2}$ is the larger sample size, $T_{1}$ is the rank sum of smaller samples, and $T_{2}$ is the rank sum of large samples.

If $n_{2} \leq 8$, calculations shall be performed by Formulas (11) and (12) respectively, while the lower value shall be considered as the value of $U$. Then consult the list of the concomitant probability of $U$ in the Mann-Whitney $\mathrm{U}$ tests in order to calculate the concomitant probability (p).
If $n_{2} \leq 8$, it will be impossible to consult the list of the concomitant probability. Then the sampling distribution of $U$ may be tested via normal approximation as follows:

$$
z=\frac{U-\frac{n_{1} n_{2}}{2}}{\sqrt{\frac{n_{1} n_{2}\left(n_{1}+n_{2}+1\right)}{12}}}
$$

...where $\mathrm{z}$ is a test statistic and other parameters have the same meanings as follows.

\section{Recognition Methods for Domain of Influence of Hydrological Variations}

Hydrological and ecological variation indexes are defined as follows. In studies about related ecological and hydrological connections, people generally employ index systems for characterizing and evaluating the health status of ecological and hydrological systems in a river basin or an area. In general, an index system is made up of a range of hydrological elements or features with ecological significance, which are external manifestations of water demands of ecological and hydrological systems.

Range of variability approach (RVA) [41] is a methoed for evaluating hydrological variations of turbid rivers on the basis of the following principles. Hydrological phases are divided based on the position of variations. In combination with indicators of hydrologic alternation (IHA), the domains of variations to hydrologic series before and after the variations are recognized (the series before and after the point of variation are called reference and variation series, respectively), in order to analyze hydrological variations in details and find out the hydrological indexes with strong variations. The range of variability approach is based on statistical analysis of ecologyrelated flow characteristics, extracting hydrological features (indexes) of 32 rivers from five perspectives, including volume, time, frequency, and time delay and change rate (Table 1).

Indexes shall be selected in line with following principles:

1) Indexes that can reflect ecological and hydrological features are selected based on river conditions and the features by fully considering water flow characteristics of rivers.

2) Take existing facts about development into account. The index selection shall not only meet ecological requirements of rivers, but also shall consider the needs for flood prevention and power supply.

3) Pay attention to whether indexes are representative. The hydrological characteristics differ across sections. The indexes selected shall be independent and representative. Meanwhile, unnecessary repetitions of indexes shall be avoided. 
4) Improve index operability in order to lay a foundation for subsequent ecological regulation.

5) Consider how difficult it is to acquire indexes and make sure that all indexes can be obtained for evaluation or characterization within certain period.

The extractions from the reference series are reckoned as disturbance thresholds, and the number of hydrological features of rivers that fall into disturbance thresholds in the series is compared to reflect the extent to which the river flow is disturbed. The degree of disturbance is generally conveyed by 32 IHA indexes and the degree of overall impacts. Hydrological indexes can reflect the degree of ecological changes when their parameters change. It is beyond doubt that significant changes of hydrological indexes result in high-strength disturbance of corresponding ecological systems. Table 1 shows particular meanings of indexes and their impacts upon ecological systems of rivers.

\section{Results and Discussion}

\section{Runoff Sequence Trend Analysis}

In this paper, the changes of ecological hydrological characteristics in the upper reaches of the Yellow River include the inter annual variability of runoff, changes in flood season, distribution during the year, extreme flow changes, hydrological extreme time, high and low flow, frequency, and rate of flow conditions. The measured runoff data of Lanzhou section were selected.

In order to determine the overall trend of the change in runoff, we will use a simple linear regression method. From Fig. 2 we get a simple equation:

$$
\begin{gathered}
Y=-4.673531106 \times X+10223.94766 \\
(R 2=0.6563)
\end{gathered}
$$

It is a significant decreasing trend that can be observed in the natural stream flow series along the entire main stream of the Lanzhou section of annual stream flow series.

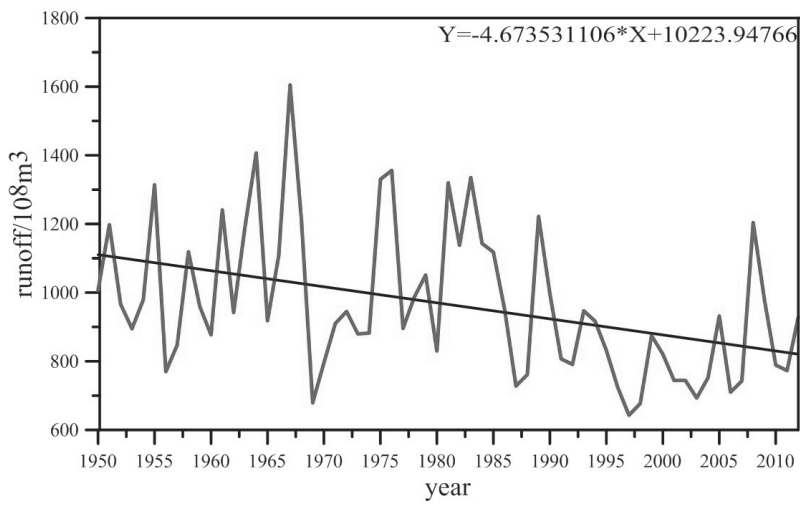

Fig. 2. Annual natural runoff change trend line of Lanzhou station.

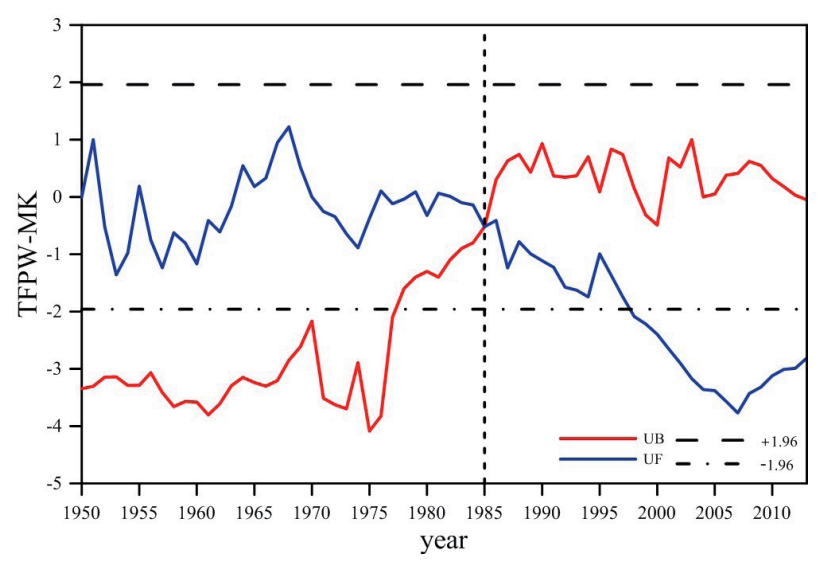

Fig. 3. Mann-Kendall test with trend-free pre-whitening.

\section{Identifying Variations}

In view of the particularity and complexity of the variance test, the TFPW-MK variance test was used to study the variation of the annual runoff series in Lanzhou section. The results of the test are shown in Fig. 3. It can be seen that the trend line UFK values are basically negative values, indicating that the runoff sequence as a whole shows a continuous downward trend, and in 1985 the runoff series has a significant downward trend, according to literature analysis, from 80. In the late $1990 \mathrm{~s}$ the temperature of the upper reaches of the Yellow River increased gradually and precipitation decreased gradually. The decrease of precipitation would naturally lead to the decrease of runoff, and the proportion of runoff change was larger than that of precipitation. Therefore, the runoff and abrupt change characteristics of the upper reaches of the Yellow River are in part to the response to precipitation change in the basin, especially in the mid-1980s.

According to the TFPW-MK mutation test, the intersection of UFK and UBK curves is located in 1985, which is the year of the runoff variation of the Lanzhou section.

\section{Mann-Whitney U Test of Results}

According to the time sequence, the rank test of the hydrological sequence is performed, and that point as the dividing point, the hydrologic sequence into two samples. Set two hypotheses:

- H0: the distribution of the two samples is the same, that is no significant difference.

- H1: the distribution of the two samples is different, there are significant differences.

- H0: the distribution of the two samples is the same, that is no significant difference.

- H1: the distribution of the two samples is different, there are significant differences.

The confidence level of $\alpha=0.05$, using bilateral quantile to test, when $\alpha=0.05$, then $Z 1-\alpha / 2=1.96$, if $|z| \leq \mathrm{Z} 1-\alpha / 2, \mathrm{H} 0$ is accepted, there was no significant 
difference between the two samples; Richard alpha $=0.05$, alpha $\mathrm{Z} 1 / 2=1.96$, if $|\mathrm{z}|>\mathrm{Z} 1-\alpha / 2$, then accept the H1, two samples have significant differences. That is, the variation occurs and takes the $|z|$ as the hydrological variation point. Table 2 is the Lanzhou section of moving rank sum test results.

Step 1, on the whole Lanzhou section of hydrologic sequence by rank sum test, and calculate the variation of the first point. When the sequence is 1950-1985, 1986-2004, the statistical test $|z|$ is the largest, and $|z|>1.96$, the test results for the rejection of $\mathrm{H} 0$, two sample distribution has significant difference.

Step 2, then find out all possible mutations. Moving rank sum test for 1950-1985. When the sequence segmentation for 1950-1963 and 1964-2004, the statistical test is the largest, the test results are rejected $\mathrm{H} 0$, and the distribution of the two samples is significantly different; the rank sum test is performed for 1986-2004, and there are no mutation points. Now, the hydrological sequence of Lanzhou section are 1950-1963, 1964-1985, and 1986-2004.

Step 3, each of the adjacent segments of the sequence into a sequence, and then analyze the mutation point. Sliding rank sum test for 1964-2004, when the sequence segmentation for 1950-1963 and 1964-1985, the statistical test is the largest, so the test results are rejected $\mathrm{H} 0$, and the distribution of the two samples is significantly different; moving rank sum test for 1950-1985, when the sequence segmentation for 1950-1963 and 1964-1985, the statistical test is the largest, so the test results are rejected $\mathrm{H} 0$, and the distribution of the two samples is significantly different. Each of the two adjacent segments are combined into a series of tests, the variation is not changed. The need to use the 2 steps again on $1950-1963$ by moving the rank sum test, there is no point mutation in this period; the rank sum test is performed for 1964-1985, and there are no mutation points in this period; the rank sum test is performed for 1986-2004, and there are no mutation points in this period. There was no mutation in each sequence. All possible variations have been identified. Finally, the hydrological variation of Lanzhou section is obtained as follows: 1950-1963, 1964-1985, and 19862004.

According to Fig. 3 showing the results of the TFPW-MK test and rank test analysis in 1963, there is no intersection with the curve and the trend line is relatively flat; it is considered that there is no variation in 1963. In 1983 the TFPW-MK test results are in agreement with the rank sum test results and show variation; it is determined 1985 for the hydrological variation of Lanzhou section.

\section{Analysis of IHA Index}

The variation time and intensity of the hydrological sequence were determined through the above analysis, but the degree of variation of each hydrological index was still unknown.

According to the above analysis, the entire hydrological time series was divided into two periods. The various amounts of human activity were represented through the two stages. We used the RVA to compare the various indicators during the 2 stages.

Stage 1: before 1985 (near-nature)

Stage 2: 1985-2012 (human impact)

It is not difficult to see that these are some hydrological indicators that change significantly more

Table 2. Main IHA indexes of rivers and their impacts upon the ecological system of rivers.

\begin{tabular}{|c|c|c|c|c|c|}
\hline Group & Content & SN & Unit & IHA & Ecological Responses \\
\hline 1 & Monthly Flow & $1 \sim 12$ & $\mathrm{~m}^{3} / \mathrm{s}$ & $\begin{array}{c}\text { Average Flow from January to } \\
\text { December }\end{array}$ & $\begin{array}{l}\text { Satisfy needs of aquatic creatures for habitats, needs } \\
\text { of plants for soil moisture, reliable water needs for } \\
\text { land creatures, migration needs of carnivores, and } \\
\text { impacts of water temperature and oxygen content }\end{array}$ \\
\hline 2 & $\begin{array}{c}\text { Annual } \\
\text { Extreme Flow }\end{array}$ & $13 \sim 23$ & $\mathrm{~m}^{3} / \mathrm{s}$ & $\begin{array}{l}\text { Annual max and min average } \\
\text { flow within 1, 3, 7, } 30 \text { and } \\
90 \text { days, baseflow index }\end{array}$ & $\begin{array}{l}\text { Satisfy the needs for vegetation expansion, creation } \\
\text { of fluvial landform and natural habitats, nutrient } \\
\text { exchange of rivers and flood retarding basins, needs } \\
\text { for distribution of plant communities in lakes, ponds } \\
\text { and flood retarding basins }\end{array}$ \\
\hline 3 & $\begin{array}{l}\text { Occurrence } \\
\text { time of annual } \\
\text { extreme flow }\end{array}$ & $24 \sim 25$ & $\begin{array}{l}\text { Julian } \\
\text { day }\end{array}$ & $\begin{array}{l}\text { Occurrence time of annual } \\
\text { max and min one-day flow }\end{array}$ & $\begin{array}{l}\text { Satisfy habitat conditions of fish migration and } \\
\text { oviposition, circulating reproduction of living crea- } \\
\text { tures, habitat conditions of the reproductive period } \\
\text { and evolutionary needs of species }\end{array}$ \\
\hline 4 & $\begin{array}{l}\text { High/low flow } \\
\text { frequency and } \\
\text { time delay }\end{array}$ & $26 \sim 39$ & count; & $\begin{array}{l}\text { Times of annual low/high- } \\
\text { pulse flow and the average } \\
\text { time delay }\end{array}$ & $\begin{array}{l}\text { Generate a frequency and measurement of soil } \\
\text { moisture necessary for plantation, satisfy needs for } \\
\text { support of aquatic creatures, sediment transport, } \\
\text { structures of river courses and bottom disturbance }\end{array}$ \\
\hline 5 & $\begin{array}{l}\text { Change rate } \\
\text { and frequency } \\
\text { of flow }\end{array}$ & $30 \sim 32$ & $\%$; count & $\begin{array}{l}\text { Annual decrease/increase rate } \\
\text { of flow; annual flow v } \\
\text { ariations }\end{array}$ & $\begin{array}{l}\text { Cause drought of plants, capture of organic matters } \\
\text { in islands or flood retarding basins and desiccation } \\
\text { stress of organisms that move at a low pace. }\end{array}$ \\
\hline
\end{tabular}




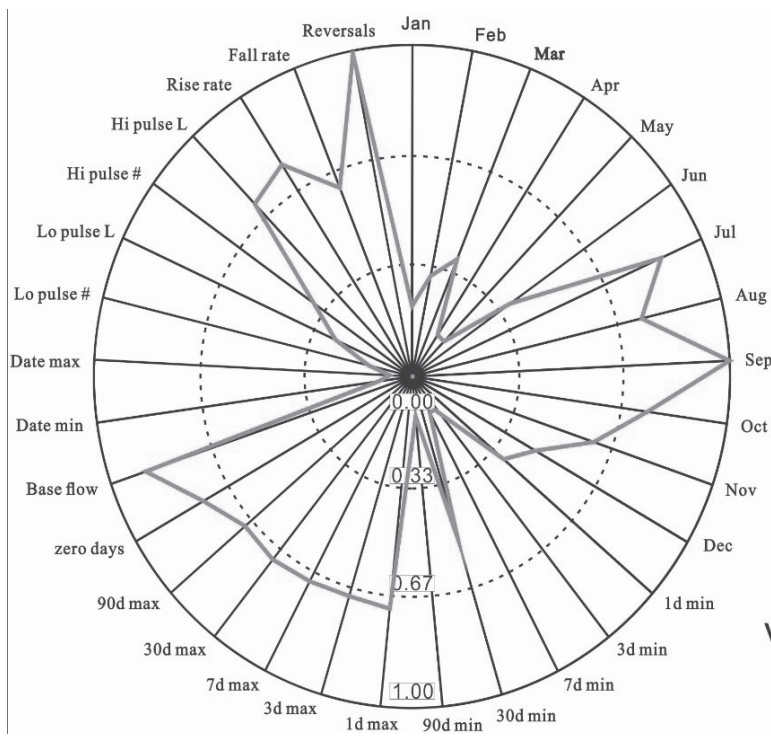

Stage 2 by Stage 1

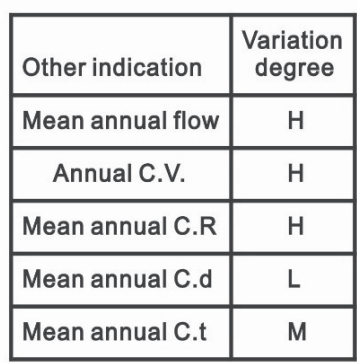

Variation degree distribution

Fig. 4. Hydrological indicator variations in Stage 2 (time of low disturbance) versus Stage 1 time of non-disturbance).

in stage 2 than in stage 1 in Fig. 4. The ecological and hydrological characteristics of Lanzhou section change greatly throughout the analysis. The comprehensive hydrologic alterations were as high as 0.61 in Stage 2 versus Stage 1, and it is a high degree of change. Among the 33 calculation indicators, 13 exhibited high, 9 moderate, 10 low, and 1 no change. One of the three indicators has a high degree of change - mostly concentrated in inter-annual variation, wet season runoff, extreme low flow, and rate of flow change indices (Fig. 5).

It is easy to understand that these new variation indicators corresponded to the operations of the reservoir. Liujiaxia Reservoir, located upstream of the hydrological station, is a power generation, both flood control, irrigation, anti-Ling, breeding and other comprehensive benefits of large-scale water conservancy project, and it is primarily been used for irrigation purposes since 1985. In the normal use of the reservoir stage, during the wet season, it collects most of the runoff from the river for irrigation purposes during the dry season. Therefore, Stage 2 of the wet season runoff is much smaller than Stage 1. Moreover, the nonflooding season and irrigation period overlap, resulting

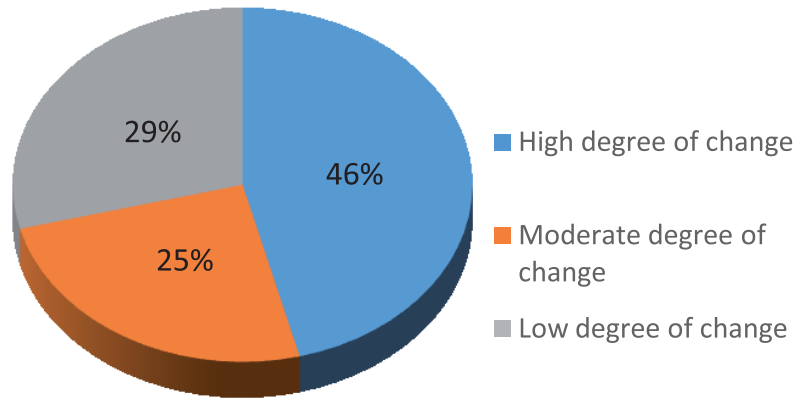

Fig. 5. Degree of indicator change. in delivery of almost no water to the downstream channels and cut-off events. Furthermore, the reservoir provided less outflow after the reservoir operation process, and reduced frequency of flow variations downstream.

According to the data, the above analytic result corresponded with the variation characteristic. So we could believe that this result is dependable.

\section{Climate Change}

Over the past century, the global climate change result in the global environmental change, and further

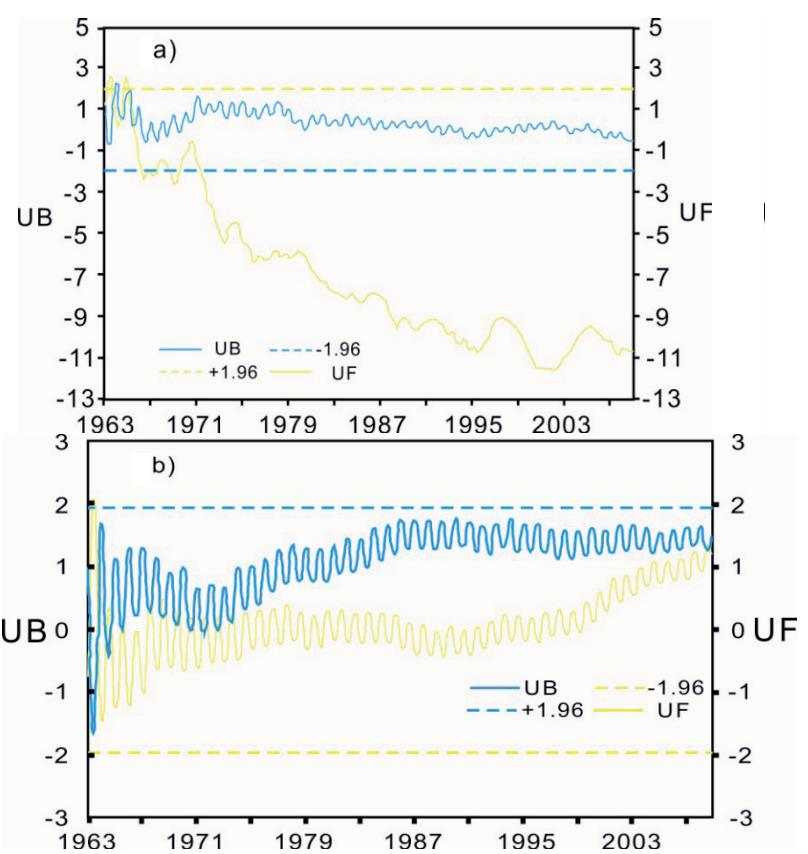

Fig. 6. Mann-Kendall test results a) for precipitation, b) for temperature. 


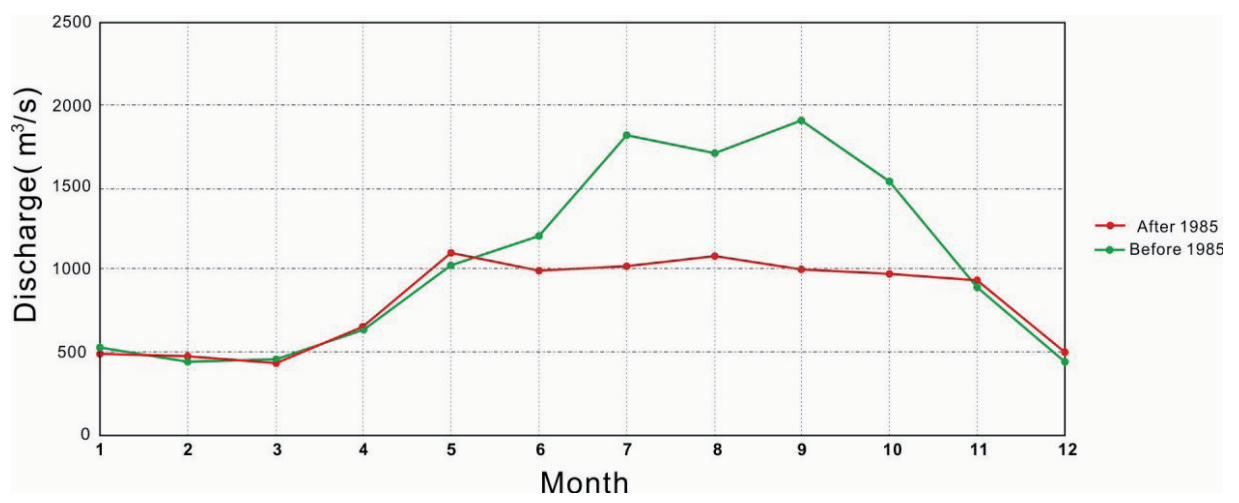

Fig. 7. Variations in the intra-annual amounts of Longyangxia Reservoir outflow.

impact on the river streamflow through variations in temperature and precipitation. So, in this paper we could verify whether the hydrological changes in the upper Yellow River were the results of climate change. We will use the MK method to test 2 meteorological series (Fig. 6). The two meteorological time series were obtained from the China Meteorological Data Network (data.cma.cn).

From the precipitation series UF curve, we found that the data was less than 0 after 1965, indicating a continuous decrease in precipitation. The concomitant result of decline in precipitation is a change in the trends of the hydrological series. However, there is no significant change point in the precipitation series UF curve. Likewise, neither the temperature exhibited any significant change points. Thus, climate change is not the first reason for the runoff variation, which is attributed to human activity.

\section{Human Activity}

More and more human activities have affected the change of hydrological time series, especially in reservoir and dam construction obstructing and altering the hydrological regimes of rivers [21]. In Fig. 7, the intra-annual outflow before and after 1985 changes are compared. This figure indicates that pre-1985 outflow differed entirely from after 1985 in both quantity and time distribution.

Although the cross-sectional runoff of the study area follows the natural hydrological model, the runoff of June to October from 1950 to 1985 and the runoff of June to October from 1985 to 2012 showed a significant change. June to October is an important flood season and irrigation period. However, due to the dam's impact on flood control and reservoir filling, the runoff in the flood season from 1985 to 2012 was significantly

Table 4. Highly changed alterations.

\begin{tabular}{|c|c|c|c|c|c|c|c|}
\hline \multirow[t]{2}{*}{ Parameter Group } & \multicolumn{2}{|c|}{$\begin{array}{c}\text { Pre-impact period: } \\
\text { 1950-1985 }\end{array}$} & \multicolumn{2}{|c|}{$\begin{array}{c}\text { Post-impact period: } \\
1986-2004\end{array}$} & \multirow[t]{2}{*}{ Deviation } & \multirow{2}{*}{$\begin{array}{c}\text { Deviation rate } \\
(\%)\end{array}$} & \multirow{2}{*}{$\begin{array}{l}\text { Hydrologic } \\
\text { Alteration }\end{array}$} \\
\hline & Medians & Dispersion & Medians & Dispersion & & & \\
\hline July Medians & 1725 & 0.64 & 946 & 0.31 & 779 & 0.45 & -0.84 \\
\hline August Medians & 1530 & 0.73 & 956 & 0.47 & 574 & 0.38 & -0.68 \\
\hline September & 1583 & 0.98 & 863 & 0.37 & 720 & 0.45 & -1 \\
\hline October & 1450 & 0.75 & 862 & 0.28 & 588 & 0.41 & -0.68 \\
\hline 1-day maximum & 3320 & 0.38 & 1680 & 0.3 & 1640 & 0.49 & -0.71 \\
\hline 3-day maximum & 3185 & 0.41 & 1453 & 0.39 & 1732 & 0.54 & -0.68 \\
\hline 7-day maximum & 3026 & 0.44 & 1340 & 0.34 & 1686 & 0.56 & -0.68 \\
\hline 30-day maximum & 2658 & 0.37 & 1170 & 0.26 & 1488 & 0.56 & -0.68 \\
\hline 90-day maximum & 1964 & 0.4 & 1060 & 0.21 & 904 & 0.46 & -0.68 \\
\hline Base flow index & 0.302 & 0.36 & 0.4754 & 0.21 & -0.1725 & -0.57 & 0.84 \\
\hline High pulse count & 4.5 & 0.78 & 2 & 2.5 & 2.5 & 0.56 & -0.68 \\
\hline High pulse duration & 7 & 1.93 & 1.5 & 2.08 & 5.5 & 0.79 & -0.71 \\
\hline Number of reversals & 145 & 0.5 & 208 & 0.05 & -63 & -0.43 & 1 \\
\hline
\end{tabular}


smaller than that from 1950 to 1955 . At the same time, Longyangxia Reservoir was built and put into use in 1985, which coincides with the hydrological variation point in the cross-section of the study area. Therefore, we can deduce from the above analysis that the most likely reason for the hydrological sequence changes in the cross-section of the study area after 1985 is the changes of people's control over the reservoir and local water consumption.

\section{Highly Changed Alterations}

According to the above analysis, there are 13 hydrological indicators to change height (Table 4).

The impacts of hydrological indices upon ecological systems are specifically analyzed as follows based on their significant changes:

1) A period of flood in July, August, September, and October when plants luxuriate and transpire heavily and require much water. Since 1985, average water flow has changed significantly in July, August, September, and October - particularly declining from $1,583 \mathrm{~m}^{3} / \mathrm{s}$ to $863 \mathrm{~m}^{3} / \mathrm{s}$. Once the decline is up to -1 , disruptive impacts will be imposed upon downstream biological species that live on discharged flood and the habitats thereby created.

2) The minimal indices generally remain unchanged, whereas maximal indices, impacted by their flood peak reduction, have declined drastically since 1985 , which suggests that the peak of a heavy flood usually only lasts one to five days. To a certain extent, significant changes to the maximum average water flow affect morphology of river channels and the creation of natural habitats.

3) By connecting highlands with overbanks, high-pulse flow may considerably transport nutrients, shape overbanks in diverse forms, maintain watercourses, and breed living creatures of the bank in order to increase biomass and diversity of living creatures inside rivers. Since the count and delay of high-pulse flow have tended to decline significantly since 1985 , biodiversity will decline.

4) Counts of flow reversal annually increase a lot, while frequency of changes to water flow conditions has significant impacted biological species of rivers in arid areas. Owing to great flow fluctuations, aquatic creatures were washed away or stranded. Sudden ebb of river tides makes it impossible to build biological seedling communities. Based on the above analysis, it may be observed that the main changes that have happened to cross-sectional flow in Lanzhou since 1985 include lower water flow in a period of flooding, fewer flood peaks, lower high-pulse flow, and higher frequency of changes to water flow conditions, which are closely associated with the fact that Lanzhou cross-sectional flow is regulated by Longyangxiang and Liujiaxia reservoirs. Since Longyangxia Reservoir was built in 1985, its joint operation with Liujiaxia Reservoir has further enhanced flood control and regulation capacities. Measures have been taken for multi-year water replenishment and storage during high flow years to discharge water during low flow years. The declined water flow in the period of flood, water supply for drought and lack of valleys have caused great changes to water flow. The water flow is too steady from July to October when the maximum average flow changes significantly. Besides, reservoirs have functions of water supply for irrigation, power generation, and flood prevention. The water supply and water flow fluctuations have become more frequent.

\section{Discussion with Other Studies}

Although previous studies have shown that global climate change, large-scale human activities, and surface evolution have all played a crucial role in the natural hydrological cycle of the basin, these studies have failed to fully address other aspects of hydrological processes, such as degree, scope of influence, and the driving force behind hydrological changes. These are crucial to the hydraulic planning and design process. Therefore, this paper assessed the impact of unknown factors on hydrological changes in hydrological processes in large river basins in order to enhance our understanding about how to balance human needs with river health.

\section{Conclusions}

By recognizing and analyzing hydrologic variations of runoff series, the following conclusions may be reached:

1) The method adopted in this paper has been coupled to test the hydrological series from multiple perspectives and comprehensively reflect variation characteristics of time series, so the resolution of its test is relatively high. Human activity plays a more important role than climate change on the runoff variation. And the more serious decrease emerging in measured flow should result from human-induced influences in recent decades.

2) After a diagnosis and analysis of variations, it has been discovered that cross-sectional hydrological and ecological indices have changed significantly since the joint operations of the aforementioned two reservoirs, which is undoubtedly extremely harmful to regional hydrological and ecological safety. It is suggested that the construction of the Yellow River eco-hydrological index system and ecological reservoir operations should be taken into full account.

3) In this paper, the cross-sections of the Yellow River in Lanzhou are exemplified to explore ecological hydrologic variations in the Yangtze River. However, there are still some problems in practice. For instance, it is necessary to particularly consider how to guide regional water resource management practices with 
analytical results of ecological hydrologic variations. The author considers that analysis of ecological hydrologic variations is supposed to be an important factor that restricts water resource management of rivers and hydraulic project planning. Hence, it will be important to put analytical results of ecological hydrologic variations into water resource management practices by establishing relationships between ecological hydrologic variation indices and water-related activities to formulate rules for construction restriction.

In this study, statistics and ecology were combined to analyze the hydrological series of large-scale river basins. The science and rationality of results have been verified by the actual conditions and the results can provide some advice on guiding river water management in the section of the study area. Therefore, this method can be popularized and perfected and be regarded as an important means to analyze hydrological phenomena and reveal its statistical laws. Because the results of this method of analysis have great influence on the rationality of engineering hydrological design data, it is of great socioeconomic significance.

\section{Acknowledgements}

We would like to extend our gratitude to the reviewers for their helpful comments that improved this manuscript considerably. We also express our gratitude to Dr. Xue from the Department of Mathematics and Information Science, Chang'an University, for his help. Our research was supported by the Special Fund for Study on Micro-scale Hydrological Ecology (310829173306), the Study on Drought Warning and Water Resources Allocation in Arid Areas and Semiarid Region (310829173701), and the Study on Water Resource Management in the Hydrological Cycle (310829172202).

\section{Conflict of Interest}

The authors declare no conflict of interest.

\section{References}

1. DAWEN Y., CHONG L., HEPING H., ZHIDONG L., SHIXIU Y., TETSUYA K., TOSHIO K., KATUMI M. Analysis of water resources variability in the Yellow River of China during the last half century using historical data. Water Resource Research, 40 (06), 502, 2004.

2. YANG T., ZHANG Q., CHEN Y.D., TAO X., XU C.Y., CHEN X.A spatial assessment of hydrologic alteration caused by dam construction in the middle and lower Yellow River. China. Hydrology Process, 22 (18), 3829, 2008.

3. TANG Q., OKI T., KANAE S., HU H.Hydrological cycles change in the Yellow River basin during the last half of the twentieth century. J Climate, 21 (8), 1790, 2008.
4. OUYANG W., HAO F., SONG K., ZHANG X. Cascade dam-induced hydrological disturbance and environmental impact in the upper stream of the Yellow River. Water Resource Manage, 25( 3), 913, 2011.

5. WU J., QIAN H., LI P.Y., SONG Y. A system-theorybased model for Monthly River runoff forecasting: model calibration and optimization. Journal of Hydrology and Hydromechanics, 62 (1), 82, 2014.

6. WEI X., ZENGCHUAN D., ZHENCHUN H., DAYONG L., LI R. River health evaluation based on the Fuzzy matter-element extension assessment model. Polish Journal of Environmental Studies, 26 (3), 1353, 2017.

7. BENESTAD R.E., HANSSEN-BAUER I., FORLAND E.J. An evaluation of statistical models for downscaling precipitation and their ability to capture long-term trends. International Journal of Climatology, 27 (5), 649, 2010.

8. BEUCHAT X., SCHAEFLI B., SOUTTER M., MERMOUD A. Toward a robust method for sub daily rainfall downscaling from daily data. Water Resource Research, 47 (9), 1995, 2011.

9. GUAN H., WILSON J.L., XIE H.J. A cluster-optimizing regression-based approach for precipitation spatial downscaling in mountainous terrain. Journal of Hydrology, 375 (3-4), 578, 2009.

10. LAMPTEY B.L. Comparison of gridded multisatellite rainfall estimates with gridded gauge rainfall over West Africa. Journal of Applied Meteorology and Climatology, 47 (1), 185, 2008.

11. APSITE E., RUDLAPA I., LATKOVSKA I., ELFERTS D. Changes in Latvian river discharge regime at the turn of the century. Hydrology Research, 44 (3), 554, 2013.

12. SCHUMANN A.Y. KANTELHARDT J.W. Multifractal moving average analysis and test of multifractal model with tuned correlations. Physica A Statistical Mechanics and Its Applications, 390 (14), 2637, 2011.

13. YUAN X.H., JI, B., TIAN H., HUANG, Y.H. Multiscaling analysis of monthly runoff series using improved MF-DFA approach. Water Resources Management, 28 (12), 3891, 2014.

14. ZHANG Q., ZHOU Y., SINGH V.P. Detrending methods for fluctuation analysis in hydrology: Amendments and comparisons of methodologies. Hydrological Processes, 28 (3), 753, 2014.

15. WANG J.H., KANG L.L., YU H., WANG Y.Z. Analysis on the Effects of Climate Change on Natural Runoff Volume in the Upper Reaches of the Yellow River In Chinese. Arid land Geography, 28 (3), 288, 2005.

16. LI P.Y., QIAN H., WU J.H.Accelerate research on land creation. Nature 510 (7503), 29, 2014.

17. POFF N.L., ZIMMERMAN J.K.H. Ecological responses to altered flow regimes: a literature review to inform the science and management of environmental flows. Fresh Biology, 55 (1), 194, 2010.

18. WANG H., YANG Z., SAITO Y., LIU J.P., SUN X., WANG Y. Stepwise decreases of the Huanghe (Yellow River) sediment load (1950-2005): impacts of climate change and human activities. Glob Planet Change, 57 (3), 331, 2007.

19. CUI B., TANG N., ZHAO X., BAI J. A managementoriented valuation method to determine ecological water requirement for wetlands in the Yellow River Delta of China. Journal for Nature Conservation, 17 (3), 129, 2009.

20. WANG J, HONG Y, GOURLEY J, ADHIKARI P, LI L, SU F. Quantitative assessment of climate change and human impacts on long-term hydrologic response: 
a case study in a sub-basin of the Yellow River China. International Journal of Climatology, 30(14), 2130, 2010.

21. LI P.Y., QIAN H., HOWARD K.W.F., WU J.H, LYU X. Anthropogenic pollution and variability of manganese in alluvial sediments of the Yellow River, Ningxia, northwest China. Environmental Monitoring \& Assessment, 186 (3), 1385, 2014.

22. REDSHAW C.H., STAHL-TIMMINS W.M., FLEMING L.E., DAVIDSON, I., DEPLEDGE M.H. Potential Changes in Disease Patters and Pharmaceutical Use in Response to Climate Change. Journal of Toxicology and Environmental Health B, 16 (1), 285, 2013.

23. PACK E.C., KIM C.H., LEE S.H., LIM C.H., SUNG D.G., KIM M.H., PARK K.H. Effects of Environmental Temperature Change on Mercury Absorption in Aquatic Organisms with Respect to Climate Warming. Journal of Toxicology and Environmental Health Part A, 77 (1), 1477, 2014.

24. LI P.Y., QIAN H., HOWARD K.W.F., WU J. Heavy metal contamination of Yellow River alluvial sediments, northwest China. Environmental Earth Sciences, 73 (7), 3403, 2015.

25. YANG Y.H., TIAN F. Abrupt Change of Runoff and Its Major Driving Factors in Haihe River Catchment, China. Journal of Hydrology, 374 (3), 373, 2009.

26. VALIPOUR M., BANIHABIB M.E., BEHBAHANI S.M. Parameters Estimate of Autoregressive Moving Average and Autoregressive Integrated Moving Average Models and Compare Their Ability for Inflow Forecasting. Journal of Mathematics and Statistics, 8 (3), 330, 2012.

27. VALIPOUR M., BANIHABIB M.E., BEHBAHANI S.M.R. Comparison of the ARMA, and the Autoregressive Artificial Neural Network Models in Forecasting the Monthly Inflow of Dez dam Reservoir. Journal of Hydrology, 476 (476), 433, 2013.

28. KÖSE E., TOKATLI C., ÇIÇEK A. Monitoring stream water quality: a statistical evaluation. Polish Journal of Environmental Studies, 23 (5), 1637, 2014.

29. GULICH D., ZUNINO L. A criterion for the determination of optimal scaling ranges in DFA and MF-DFA. Physica A Statistical Mechanics and Its Applications, 397 (397), 17, 2014.
30. STONEVICIUS E., VALIUSKEVICIUS G., RIMKUS E., KAZYS, J. Climate induced changes of Lithuanian Rivers runoff in 1960-2009. Water Resources, 41 (5), 592, 2014.

31. DAZBROWSKA J., BAWIEC A., PAWELKKA K., KAMIŃSKA J., STODOLAK R. Assessing the Impact of Wastewater Effluent Diversion on Water Quality. Polish Journal of Environmental Studies, 26 (1), 9, 2017.

32. RICHTER B.D., BAUMGARTNER J.V., BRANN D.P., POWELL J. A Spatial Assessment of Hydrologic Alteration within a River Network. Regulated River: Research and Management, 14 (4), 329, 1998.

33. KENDALL M.G. Rank correlation measures. London: Charles Griffin: 110, 1976.

34. MANN H.B. Non-parametric tests against trend. Econometrical. 13,245, 1945.

35. ZHANG D., CONG Z.T., NI G.H. Comparison of three Mann-Kendall methods based on the China's meteorological data In Chinese. Advances in Water Science, 24 (4), 491, 2013.

36. AZIZ O.I., BURN D.H. Trends and variability in the hydrological regime of the Mackenzie River Basin. Journal of Hydrology, 319 (1), 282, 2006.

37. HAMED K.H. Enhancing the effectiveness of prewhitening in trend analysis of hydrologic data. Journal of Hydrology, 368 (1), 143, 2009.

38. ZHANG Q., SUN P., JIANG T., TU X., CHEN X. Spatiotemporal patterns of hydrological processes and their responses to human activities in the Poyang Lake basin, China. Hydrological Sciences Journal, 6 (2), 305, 2011.

39. THEIL H. A Rank-Invariant Method of Linear and Polynomial Regression Analysis I-III. Springer Netherlands, 12 (2), 345-381, 1950.

40. SEN P.K. Estimates of the Regression Coefficient Based on Kendall's Tau. Journal of the American Statistical Association, 63 (324), 1379, 1968.

41. SHENG Y., WANG C.T. The Mann-Kendall test modified by effective sample size to detect trend in serially correlated hydrological series. Water Resources Management, 18 (3) 201, 2004. 